\title{
Early Atlantoaxial Subluxation in Enthesitis-related Arthritis
}

ABDULLATIF AL ENAZI, MD; KIM MORISHITA, MD; ROBYN A. CAIRNS, MD; LORI TUCKER, MD; DAVID CABRAL, MD; ROSS PETTY, MD; JAIME GUZMAN, MD; Department of Radiology and Division of Pediatric Rheumatology, British Columbia Children's Hospital and University of British Columbia, Vancouver, Canada. Dr. Al Enazi is now at King Fahad Medical Center in Saudi Arabia. Address correspondence to Dr. J. Guzman, British Columbia Children's Hospital, Pediatrics, 4500 Oak St., Suite K4-122, Vancouver, British Columbia V6H 3N1, Canada. E-mail: jguzman@cw.bc.ca.

J Rheumatol 2014;41:1190-1; doi:10.3899/jrheum.131206

Atlantoaxial subluxation is well recognized as a late complication of juvenile arthritis ${ }^{1}$. Early subluxation is uncommon, but it has been reported in 2 patients with juvenile ankylosing spondylitis $(\mathrm{AS})^{2,3}$ and in 2 patients with juvenile idiopathic arthritis (JIA) $)^{4,5}$.

A 12-year-old girl was diagnosed with JIA, enthesitis-related arthritis (ERA) subtype, in March 2012 when she presented with a 1-year history of joint pain and stiffness. She was positive for HLA-B27, and a great uncle had AS. On examination she had arthritis in several proximal interphalangeal joints, the left ankle, right knee, and right midfoot, and inflammation of the left Achilles enthesis. Her cervical and lumbar spine examinations were normal. She was treated with naproxen, prednisone, and methotrexate (MTX). Because of ongoing active disease, her MTX was increased, and sulfasalazine was added in September 2012.

In early December 2012 she reported a 1-month history of mild neck discomfort. Her neck examination was normal. Late that month she presented to her local emergency department with severe acute neck pain and restriction of motion. Her neck was immobilized and she was airlifted to our hospital. Radiographs (Figure 1) and magnetic resonance imaging (MRI; Figure 2) demonstrated severe C1-C2 subluxation. There was no history of major trauma and she was neurologically intact. She underwent posterior C1, C2 fusion with no complications (Figure 3), and etanercept was recommended. At followup after surgery, her parents reported that she had had chiropractic manipulation to her neck to treat neck pain before the subluxation was identified.

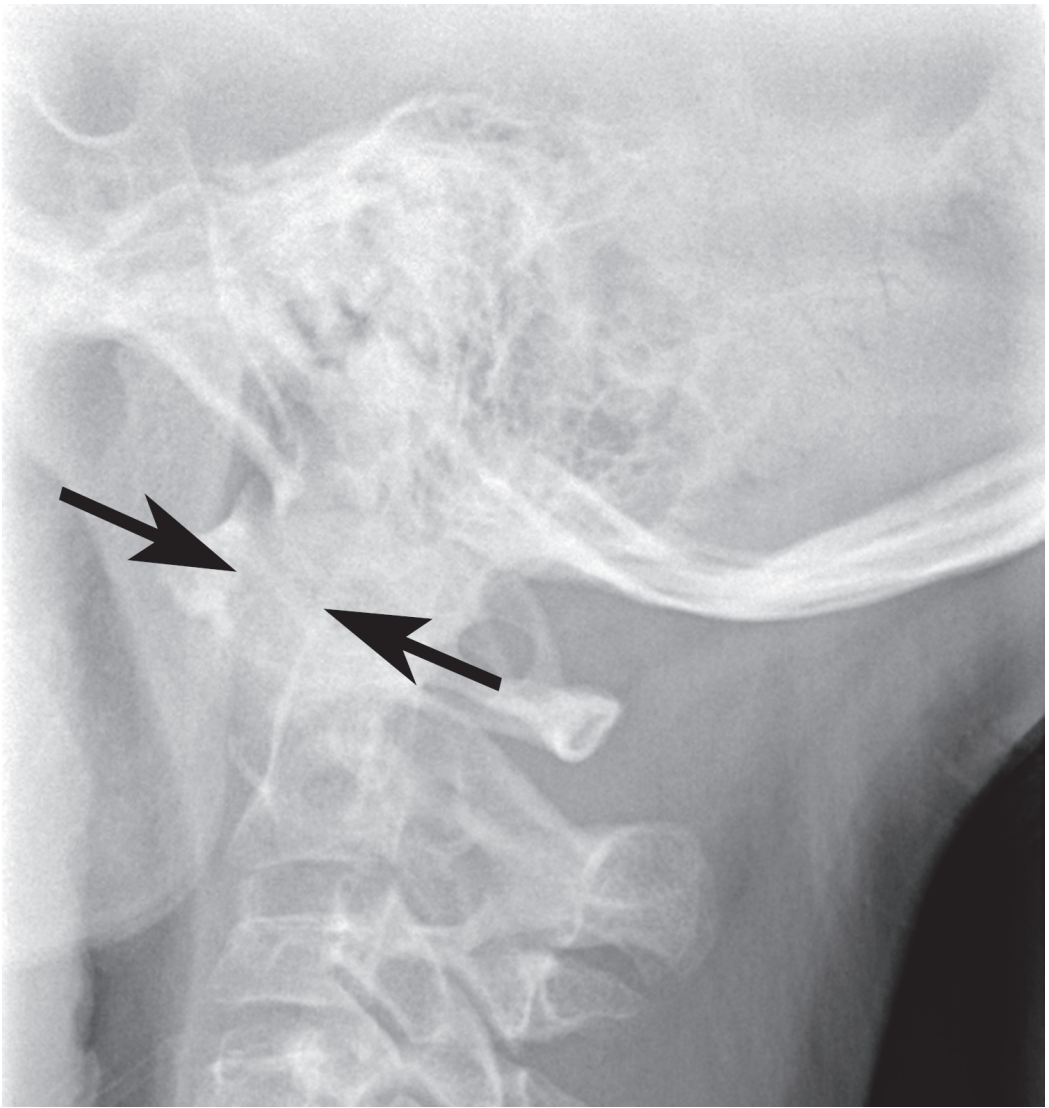

Figure 1. Radiograph demonstrated severe C1-C2 subluxation with increased distance between the anterior arch of $\mathrm{C} 1$ and the anterior cortex of the odontoid (arrows). 


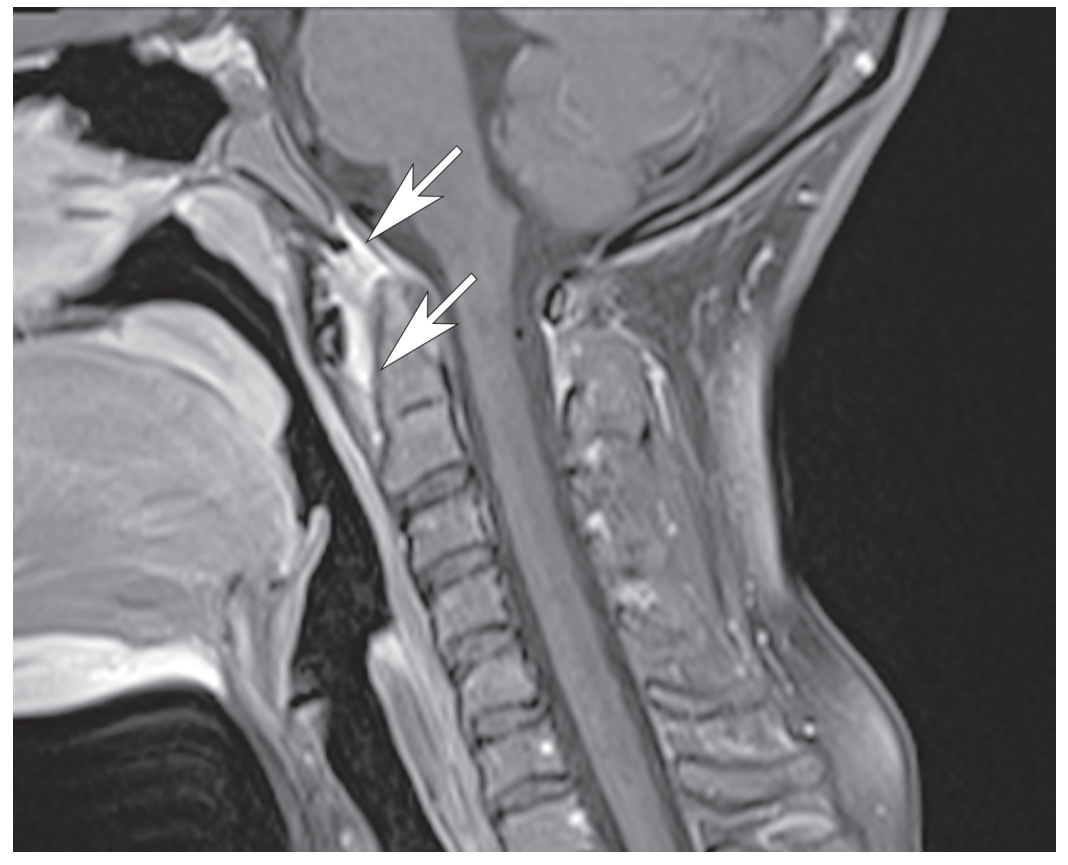

Figure 2. A contrast-enhanced cervical spine magnetic resonance image demonstrated increased separation of the anterior arch of $\mathrm{C} 1$ from the dens, measuring $5 \mathrm{~mm}$, with enhancing soft tissue between the tectorial membrane, anterior arch of $\mathrm{C} 1$, and around the dens, in keeping with enhancing synovium (arrows)

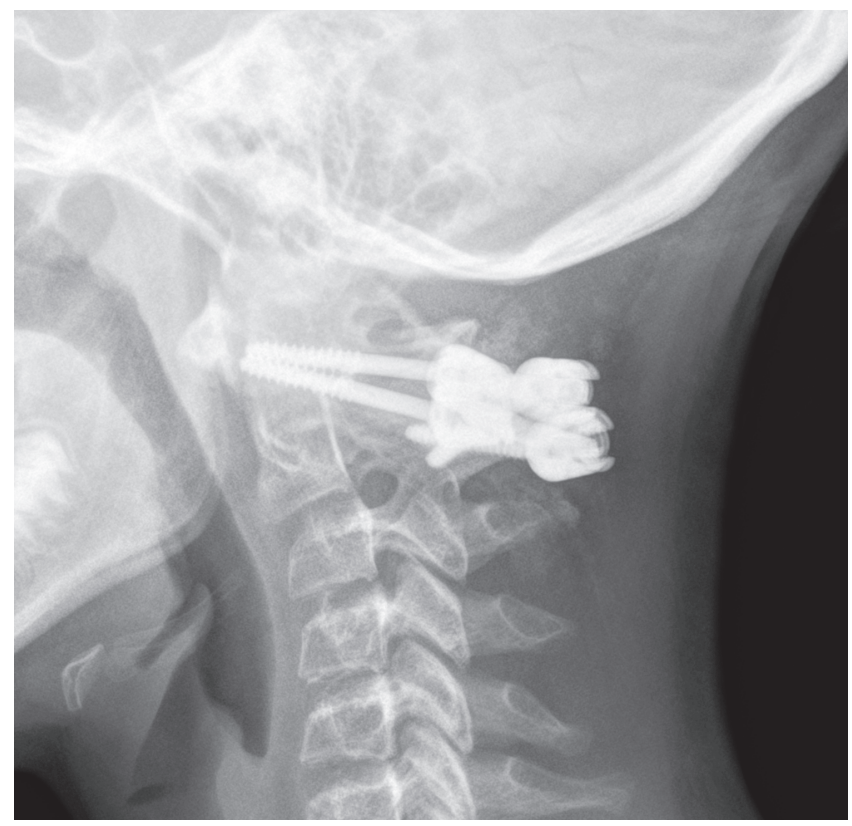

Figure 3. Postsurgery radiograph shows posterior $\mathrm{C} 1, \mathrm{C} 2$ instrumentation and fusion with $\mathrm{C} 1$ lateral mass screws and $\mathrm{C} 2$ laminar screws.
Clinicians should be aware that atlantoaxial subluxation can occur in children with ERA early in the disease. In our case, the MRI demonstrated synovitis at the atlantoaxial joint, and it is possible that neck manipulation precipitated an acute subluxation. Parents of children with JIA should be cautioned against use of manipulation for neck complaints in their child.

\section{REFERENCES}

1. Hensinger R, Devito D, Ragsdale C. Changes in the cervical spine in juvenile rheumatoid arthritis. J Bone Joint Surg 1986;68A: 189-97.

2. Breda L, Palazzi C, de Michele G, De Sanctis S, Chiarelli F. Spontaneous atlantoaxial subluxation as a presenting manifestation of juvenile ankylosing spondylitis in a female HLA-B27-negative patient. Eur J Pediatr 2005;164:455-7.

3. Thompson GH, Khan MA, Bilenker RM. Spontaneous atlantoaxial subluxation as a presenting manifestation of juvenile ankylosing spondylitis: a case report. Spine 1982;7:78-9.

4. Taddio A, Pellegrin MC, Gregori M, Wientroub S, Padeh S, Lepore L. Atlanto-axial joint involvement as exclusive manifestation of juvenile idiopathic arthritis (JIA). Clin Exp Rheumatol 2011;29:755.

5. Haasbeek JF, Lessard JA. Isolated atlantoaxial rotatory fixation in a child with seronegative spondyloarthropathy presenting with torticollis. J Rheumatol 1998;25:169-72. 